\title{
Futebol, política e identidade no Brasil
}

\author{
Football, Politics and Identity in Brazil
}

\author{
Marcel Vejmelka \\ Universidade de Mainz/Alemanha \\ Doutor em Estudos latino-americanos/brasileiros, Freie Universität Berlin \\ vejmelka@uni-mainz.de
}

\begin{abstract}
RESUmo: Devido à sua extraordinária importância cultural e social, o futebol no Brasil é um elemento decisivo para a esfera política que tenta aproveitar o esporte para os seus fins. Ao mesmo tempo, no nível da micropolítica, é a dimensão que articula grande parte das dinâmicas sociais e culturais, da identificação individual e coletiva com um time ou clube até às mais variadas formas de comunicação e codificação midiática. Dentro dessa polaridade, o futebol vem sendo um dos veículos privilegiados e um dos campos mais cobiçados para a concepção e concretização de identidades clubísticas, locais e regionais, culminando nas propostas identitárias nacionais do "país do futebol" e do "melhor futebol do mundo". Essa dinâmica acompanha, articula, visualiza e até origina as rupturas que vem marcando o Brasil enquanto nação na sua história recente.
\end{abstract}

PALAVRAS-CHAVE: Futebol brasileiro; Identidade nacional; Cultural popular; Política.

ABSTRACT: Because of its extraordinary cultural and social importance, football in Brazil constitutes a decisive element for the political sphere, where the sport is used for particular interests. At the same time, on the level of micropolitics, football strongly articulates the social and cultural dynamics of individual and collective identification with a team, as well as the most varied forms of midiatic communication and codification. Within this polarity, football has been a privileged instrument and one of the most valued grounds for the conception and concretization of team-related, local and regional identities, also for proposals of national identity in the "country of football" and "home of the world's best football". These dynamics support, articulate, visualize and even originate the ruptures which have been characterizing Brazil as a nation throughout its recent history.

KEYwoRDS: Brazilian Football; National identity; Popular culture; Politics. 


\section{INTRODUÇÃo}

Devido à sua extraordinária importância cultural e social, o futebol no Brasil é um elemento decisivo para a esfera política, que tenta aproveitar o esporte para os seus fins. Ao mesmo tempo, no nível da micropolítica, representa uma dimensão que articula grande parte das dinâmicas sociais e culturais, da identificação individual e coletiva com um time ou clube até às mais variadas formas de comunicação e codificação midiática, como explica o politólogo alemão Wolfgang Muno: "Das Verhältnis von Fußball und Politik ist nicht so eindimensional, wie es sich Krockow vorstellte. Fußball wird nicht nur von autoritären Regimen zu Manipulationszwecken missbraucht. Er ist, wie Sport allgemein, eine potenzielle Machtressource im politischen Spiel“. ${ }^{1}$ E o especialista em comunicação e mídia Holger Ihle resume os significados políticos do futebol na perspectiva dos estudos sociais:

Ein breiter angelegtes Verständnis politikwissenschaftlicher Forschungsinteressen betrachtet dagegen nicht die (demokratisch) legitimierten Institutionen als Ausgangspunkte politischer Machtausübung, sondern sieht diese vielmehr selbst verschiedenen Zwängen unterworfen. In den Fokus geraten somit auch wirtschaftliche Akteure, nationale und transnationale Organisationen und bezogen auf den Sport auch Verbände, Sponsoren und Medienunternehmen. Diese Akteure stehen nicht nur mit staatlichen Institutionen, sondern auch untereinander im Wettbewerb um Einfluss auf den Sport. ${ }^{2}$

Dentro dessa polaridade, o futebol vem sendo um dos veículos privilegiados e um dos campos mais cobiçados para a concepção e concretização de identidades clubísticas, locais e regionais, culminando nas propostas identitárias nacionais do Brasil enquanto "país do futebol" e pátria do "melhor futebol do mundo". Waldemyr Caldas, em um texto fundamental para a reflexão sobre o futebol brasileiro na Alemanha, afirma:

\footnotetext{
${ }^{1}$ MUNO. Fußball und Politik in Lateinamerika, p. 24.

2 IHLE. Die Fußball-WM 2014 in Brasilien als Sportgroßveranstaltung, p. 14. "Uma compreensão mais ampla, guiada pelo conhecimento das ciências políticas, por sua vez não contempla as instituições (democraticamente) legitimadas como pontos de partida do exercício do poder político, mas enxerga a elas como subjugadas, elas mesmas, a diferentes coerções. Assim, atores econômicos também entram em foco, organizações nacionais e internacionais e, no contexto esportivo, também associações, patrocinadores e empresas mediáticas. Esses atores estão competindo pela influência no esporte, não somente com as instituições públicas, mas também entre si".
} 
Es ist nicht zu bestreiten, daß Massenphänomene vom Kaliber des Fußballs (oder des Karnevals) auch eine politische und ideologische Funktion erfüllen. Doch wäre es naiv, diesen Bereich für so eindimensional zu halten, wie es jene Kritiker tun, die ohne weitere Prüfung unterstellen, daß die angestrebte soziale Kontrolle auch funktioniert. [...] Die eigentliche Frage lautet daher: Welche politischen Effekte hat »futebol« unter den spezifisch brasilianischen Bedingungen bewirkt? ${ }^{3}$

Revendo a história do futebol brasileiro, particularmente na sua dimensão internacional, representada pela seleção, e revendo a bibliografia existente a respeito, fica evidente que há uma espécie de contraponto entre a evolução da filosofia do jogo no Brasil - no seu duplo sentido - e os rumos políticos do país nas respectivas épocas. Não se trata de analogias ou paralelismos, e sim de entrelaçamentos e correspondências indiretas e em descompassos históricos. Simoni Guedes, uma pioneira nos estudos do futebol brasileiro, já em 1977 propôs o conceito da "instituição zero", para descrever os mecanismos de significação profunda e ampla que o futebol é capaz de produzir no contexto sociocultural brasileiro. Num estudo mais recente, ela explica:

En el caso brasileño, el fútbol se ha presentado como un vehículo casi insuperable para la producción y reproducción de estos discursos sobre la nación y el «pueblo brasileño», sustentando toda una semántica sobre el estilo nacional y la brasileñidad. En las canchas de fútbol, las narraciones sobre el ser brasileño encontrarían su espacio de elección. En este sentido, el fútbol sería la «zona libre» brasileña con mayor potencial de significación. En verdad, sería una «institución cero». 4

De forma semelhante, o estudioso alemão Thomas Fatheuer carateriza o papel do futebol nas concepções identitárias brasileiras: "Eine so konstruierte brasilianische Identität beruht selbstverständlich nicht auf dem Fußball, aber der Fußball ist eines ihrer konstitutiven Elemente und gleichzeitig ist das Sprechen über Fußball die privilegierte Sprache, mit der über Nation und Identität

\footnotetext{
${ }^{3}$ CALDAS. Brasilien, p. 179. "Não se pode negar que fenômenos de massas do peso do futebol (ou do carnaval) cumprem também um papel político e ideológico. Mas seria ingênuo pensar que essa questão é unidimensional, como fazem aqueles críticos que sem questionamento acreditam que esse intencionado controle social funciona de fato. [...] A pergunta deveria ser: Quais efeitos políticos originou o futebol sob as condições especificamente brasileiras?"

${ }^{4}$ GUEDES. El Brasil reinventado, p. 94.
} 
reflektiert werden kann". ${ }^{5}$ Esta construção identitária brasileira, focada através do futebol, está marcada por contradições e polaridades que a tornam particularmente interessante; ela está atravessada pelos conflitos, problemas sociais e políticos que constituem o fundamento do Brasil enquanto nação. Na sua evolução histórica, que contém muitos elementos suficientemente conhecidos e estudados, o jogo bretão importado e elitista se transforma, violentamente, em esporte popular e nacional. A melhor e mais expressiva síntese dessa evolução, focada na importância e forma que esse esporte foi adquirindo no Brasil, é formulada pelo uruguaio Eduardo Galeano, no seu livro clássico sobre a história mundial do futebol:

Simultáneamente, el fútbol se tropicalizaba en Rio de Janeiro y San Pablo. Eran los pobres quienes lo enriquecían, mientras lo expropiaban. Este deporte extranjero se hacia brasileño a medida que dejaba de ser el privilegio de unos pocos jóvenes acomodados, que lo jugaban copiando, y era fecundado por la energía creadora del pueblo que lo descubría. Y así nacía el fútbol más hermoso del mundo, hecho de quiebres de cintura, ondulaciones de cuerpo y vuelos de piernas que venían de la capoeira, danza guerrera de los esclavos negros, y de los bailongos alegres de los arrabales de las grandes ciudades. ${ }^{6}$

O primeiro marco dessa história é o Campeonato Sul-Americano de Futebol de 1919, torneio sediado pelo Brasil e no qual a seleção brasileira, comandada por Arthur Friedenreich, conquista o seu primeiro título internacional. Nesse momento, o futebol mal começa a jogar um papel simbólico para a unificação nacional, marcada pela urbanização e imigração massivas. E um "mulato" como Friedenreich, apesar de ser reconhecido como jogador mais importante da época, logo cai no esquecimento, morre na pobreza e só passa a ser craque venerado na sua dimensão nacional muito mais tarde, na retrospectiva. ${ }^{7}$ A profissionalização do futebol a partir dos anos 1930 é que abre as portas à diversidade étnica e, principalmente, à presença de jogadores negros. Os primeiros sucessos

\footnotetext{
${ }^{5}$ FATHEUER. Brasilien vom Fußball aus denken, p. 87. "Uma identidade brasileira assim construída, se baseia evidentemente não somente no futebol, mas o futebol é um de seus elementos constitutivos, ao mesmo tempo o falar sobre futebol representa a linguagem privilegiada para refletir sobre a nação e a identidade."

${ }^{6}$ GALEANO. El fútbol a sol y sombra, p. 34.

${ }^{7}$ Cf. CURI. Friedenreich. Na perspectiva alemã, essa biografia crítica do "gênio esquecido do futebol brasileiro" representa uma verdadeira joia.
} 
internacionais tornam o futebol em plataforma de projeção identitária de um Brasil moderno, mestiço (uma "democracia racial") e "país do futuro". ${ }^{8}$

Outra data-chave é a Copa do Mundo de 1938 na França, onde o Brasil acaba em terceiro lugar e inaugura seu papel singular no palco global. 0 público europeu se entusiasma com a forma de jogar, consolidando as bases para a concepção de um futebol genuinamente brasileiro, de estética própria e capaz de vencer, tudo simbolizado no craque da década, Leônidas da Silva. Ele representa um Brasil em vias de unificação política e cultural forçada pelo governo Vargas: "Leônidas's success was seen not just as good fortune but as a national vindication since he embodied the essence of Brazil. Football played à la brßesilienne was already the most potent symbol of nationhood - two decades before Brazil eventually won a World Cup". 9

Nos anos seguintes, personagens centrais como Gilberto Freyre e Mário Filho contribuem de forma decisiva para a mitologia do "futebol mulato",10 marcado pelo ritmo e a elasticidade dos jogadores negros e mestiços, estabelecendo uma correspondência com a mitologia política do Estado Novo que descreve o Brasil como "democracia racial" e "nação mestiça".

No Brasil, o mito do futebol nasceu junto com outro mito do qual não pode se desvencilhar. Há uma coincidência histórica que marcou para sempre o seu DNA, configurando decisivamente o seu peso no imaginário da nação. É que ele surgiu como potência e diferença justamente no momento em que se articulava, no país tardo-escravocrata, a nova imagem, partilhada por intelectuais da elite e pelo povo, do Brasil moderno, popular e mulato. Seria pouco dizer que o futebol, junto com a música popular, tornou-se a partir daí um dos pilares fundamentais desse mito. Melhor seria dizer que ele se confundiu de tal modo com esse mito que o mito passou a ser ele. ${ }^{11}$

\section{NO COMPASSO DAS COPAS (1950-70)}

O trauma de 1950 faz desmoronar esta construção e evidencia a fragilidade da identidade projetada não só, mas, sobretudo através do futebol. Ele vem sendo

\footnotetext{
${ }^{8}$ Para o futebol carioca, cf. MIRANDA PEREIRA. Footballmania. Vale lembrar o conto "Corinthians (2) vs. Palestra (1)", em Brás, Bexiga e Barra Funda, de António de Alcântara Machado, de 1927, que enfoca o futebol enquanto elemento da emergente cultura popular a partir da perspectiva modernista (cf. ALCÂNTARA MACHADO. Brás, Bexiga e Barra Funda).

${ }^{9}$ BELLOS. Futebol, p. 39-40; cf. também ZEYRINGER, Fußball, p. 141s.

${ }^{10}$ FILHO. O negro no futebol brasileiro; FREYRE. Prefácio.

${ }^{11} \mathrm{KAZ}$; COSTA E SILVA. Dando tratos à bola, p. 77-78.
} 
estudado de forma intensiva e extensiva no Brasil e pelo mundo afora e a catástrofe de 2014 está tomando o mesmo rumo. ${ }^{12}$ Entre essas duas datas marcantes, um recorrido rápido pelo andamento da seleção brasileira nas copas do mundo mostra a inter-relação complexa entre mundiais de futebol e a situação interna (político-social) no Brasil.13 Não se trata de uma mera narração linear, a relação entre a dimensão política e a futebolística na história das copas do mundo é que faz surgir a articulação de uma visão coletiva, mesmo que bem particular, da Nação, como sintetiza Martin Curi no seu impressionante livro sobre o futebol brasileiro:

Es wird deutlich, dass sich Brasilianer in dem Vierjahresrhythmus der FußballWeltmeisterschaften ihre Geschichte erzählen, was zu einer modernen Legendenbildung führt. [...] Denn wichtig ist, dass die Brasilianer anhand des Fußballs Geschichten über sich erzählen, in denen sie ihre Weltanschauung und ihre Identität definieren. ${ }^{14}$

O jogo, os sucessos e os fracassos da seleção nas copas do mundo originam, portanto, narrativas coletivas entrelaçadas com os discursos identitários existentes e concorrentes. De forma semelhante, nos seus "fragmentos" de uma teoria do futebol brasileiro, Thomas Fatheuer propõe uma visão complexa e contraditória da inter-relação entre futebol e política no Brasil:

Hier soll keineswegs einer vulgärsoziologischen Vorstellung von einer Determination des Fußballs durch die gesellschaftliche Entwicklung das Wort geredet werden. Interessant und hochwichtig aber ist, dass die Diskurse über den Entwicklungsweg Brasiliens und den Fußball deutliche Parallelen aufweisen. Anders gesagt: das Reden über Fußball ist auch eine große populäre Debatte über das Land und die Politik. ${ }^{15}$

\footnotetext{
12 PERDIGÃO. Anatomia de uma derrota; CORNELSEN, A memória do trauma de 1950; BELLOS, The fateful final; ROCCO JR. Brasil 1 x 7 Alemanha; EICHLER, 7:1 - Das Jahrhundertspiel.

${ }^{13}$ Cf. CURI. Brasilien, p. 42ss.

${ }^{14}$ CURI. Brasilien, p. 74. "Fica evidente que os brasileiros narram a sua história no ritmo quadrianual das copas do mundo de futebol, o que faz surgir uma mitologia moderna. [...] $O$ importante é que através do futebol os brasileiros contam histórias sobre si mesmos, onde eles vão definindo a sua visão do mundo e a sua identidade."

${ }^{15}$ FATHEUER. Fragmente einer Theorie des brasilianischen Fußballs, p. 117. "Não quero propagar a ideia sociologizante de que o futebol seria determinado pela evolução social. Porém é interessante e muito importante que os discursos sobre a evolução do Brasil e do futebol mostram paralelismos nítidos. Ou seja, o falar sobre futebol também é um grande debate popular sobre o país e a política".
} 
Os elementos centrais dessas narrativas, mitologias e discursos vêm sendo estudados de forma exaustiva desde há mais de 60 anos. Um dos símbolos mais famosos e potentes é o "complexo de vira-latas" formulado por Nelson Rodrigues, quem, nas suas crônicas futebolísticas, parte do trauma de 1950 para narrar, copa a copa e os altos e baixos da Brasil-Nação espelhado na sua seleção de futebol, recuperando a sua dignidade com o primeiro campeonato em 1958 e seguindo a mesma lógica entre o "melhor futebol do mundo" e o "complexo de vira-latas" até 1970, quando parece que o Brasil se coroa definitivamente enquanto tricampeão do mundo: "Essa derrota é como uma morte, e a morte pode ser um ato fundador e um reinício. A partir dela, nasce o moderno futebol brasileiro, e Nelson o acompanha com atenção e paixão, vendo no jogo a expressão ambígua da alma nacional".16

Nelson Rodrigues parece analisar a psique e a alma do Brasil, caracterizando a atuação, o "escrete" brasileiro nas copas por ele acompanhadas: Superando o trauma de 1950 com o campeonato de 1958 (passando por uma atuação intimidada e medrosa em 1954), fortalecendo a convicção da invencibilidade com o bicampeonato de 1962, recaindo na crença da superioridade europeia em 1966 e voltando ao trono como "os melhores do mundo" para a eternidade em $1970 .{ }^{17}$

Estabelecendo alguns possíveis paralelismos com a política de Estado, o campeonato de 1958 combina perfeitamente com a era Kubitschek, que quer levar o Brasil às pressas à modernidade. Como explica o historiador Walther Bernecker, naquele momento "simplesmente tudo parecia possível. E em 1958 o Brasil até foi campeão mundial". ${ }^{18} \mathrm{E}$ nos anos 1960, os discursos sobre o futebol brasileiro no contexto global se cruzam com os debates sobre o subdesenvolvimento e as saídas dessa condição periférica e atrasada (ainda que em outra perspectiva do que a do “reacionário" Nelson Rodrigues).

A mesma lógica encontra a sua uma expressão no eterno conflito do futebol brasileiro entre o ideal do "futebol-arte" ou "jogo bonito" e a ânsia pura pela vitória

\footnotetext{
${ }^{16}$ ZANIN. Nelson Rodrigues e o mito do futebol, p. 143. Vale a pena também rever os estudos de HENRIQUES. Estilística e futebol; HENRIQUES; ARAUJO. À sombra das crônicas imortais.

${ }^{17} \mathrm{Cf}$. VEJMELKA. O futebol como palco em Nelson Rodrigues.

${ }^{18}$ BERNECKER. Eine kleine Geschichte Brasiliens, p. 262.
} 
e título, o futebol de resultados. Trata-se de uma discussão de caráter universal, que em diferentes contextos culturais adquire formas distintas, mas que no Brasil é de uma importância singular e simboliza a utopia de que a beleza do jogo poder ser, ao mesmo, o jogo mais poderoso e exitoso. A própria origem desta mitologia do futebol-arte está na história do futebol brasileiro no palco internacional, nasce com as primeiras atuações da seleção em solos europeus nos anos 1930 e se impõe irreversivelmente com o tricampeonato de 1970.

Todas essas posições, as discussões e conflitos que vem se desenvolvendo ao longo da história do futebol no Brasil em torno do jogo, já por si encorparam a sua dimensão micropolítica. Esta está ligada estreitamente com a dimensão política em termos gerais, e que vai acompanhando essa história. Assim, numa forma mais nítida, o regime militar tira proveito do tricampeonato de 1970 (aliás, transmitido, pela primeira vez na história, ao vivo e em cores e globalmente pela TV). Uma das contradições históricas é que a seleção joga um futebol muito livre e criativo, liderada nas eliminatórias pelo técnico João Saldanha, e substituído pouco antes do início do torneio pelo mais conformista Zagallo. Assim o resume Mirco Drewes, na sua ótima história do futebol brasileiro, publicada na Alemanha:

Die Demonstration von Aufschwung und Wohlstand sollte über die Realität der meisten hinwegtäuschen. Auf den Fußball setzte die Militärdiktatur dabei besonders. Statt sozialer Programme wurden riesige Fußballstadien gebaut und die Seleção zum nationalen Symbol aufgebaut. Zwar hatte der Fußball stets ein Modell für gesellschaftliche Teilhabe und Gleichheit der verschiedenen Ethnien und sozialen Schichten abgegeben, doch ebenso gut konnte er, geschickt instrumentalisiert, über die realen Unterschiede hinwegtäuschen. ${ }^{19}$

\footnotetext{
${ }^{19}$ DREWES. Samba tanzt der Fußballgott, p. 163. "Essa demonstração de crescimento e bemestar deveria encobrir a realidade da maioria. Nisso, a ditadura militar apostava especialmente no futebol. Em vez de programas sociais, se construíram gigantescos estádios, e a seleção foi encenada como símbolo nacional. O futebol sempre tinha sido um modelo de participação social e da igualdade das diferentes etnias e camadas sociais, mas da mesma maneira podia ser instrumentalizado com destreza e dissimular as diferenças reais."
} 


\section{“VENCER O CAMPEONATO É O MENOR DETALHE”? (1974-1990)}

No outro extremo encontramos a posição otimista de Roberto DaMatta, atribuindo ao futebol uma força libertadora ou, pelo menos, democratizante, na sua dimensão sociopolítica:

[0] futebol proporciona à sociedade brasileira a experiência da igualdade e da justiça social [...] No caso brasileiro, foi indiscutivelmente através do futebol, como já afirmei, que o povo pôde finalmente juntar os símbolos do Estado nacional (a bandeira, o hino e as cores nacionais), esses elementos que sempre foram propriedade de uma elite restrita e dos militares. ${ }^{20}$

Essa interpretação carnavalesca de DaMatta tem algo em comum com o mito latino-americano de um futebol substancialmente político, articulado da maneira mais conhecida pelo técnico argentino Menotti e pelo já citado Eduardo Galeano, e que tem grande influência na importância simbólica do esporte nas representações identitárias, pois quebra a lógica linear da identidade nacional "reacionária" e contribui para a sua continuidade histórica. ${ }^{21}$

Depois da decepcionante atuação do Brasil em 1974, a copa de 1978 na Argentina mostrou de forma extrema a instrumentalização do futebol pela política, no caso pela ditadura militar. Mas os sucessos decisivos acontecem em outro campo, principalmente no da política nacional, com a hoje mítica "democracia corintiana" no início dos anos 1980, marcada por um papel ativo no retorno à democracia, com jogadores conscientes, militantes e de esquerda. Revigora o mito do futebol político, do futebol enquanto ferramenta ativa da mudança política progressista.

Als der junge Werbefachmann Washington Olivetto von den Entwicklungen bei Corinthians hört, erfindet er den Namen Democarcia Corinthiana, ein perfektes branding. Auch der Slogan "Meisterschaft ist nur ein Detail", der Sócrates zugesprochen wird, erweist sich bis heute als eine geniale Synthese des damaligen Zeitgeistes. ${ }^{22}$

\footnotetext{
${ }^{20}$ DAMATTA. Antropologia do óbvio, p. 17.

${ }^{21}$ DUNKHORST. Linker Fußball? Rechter Fußball?; GALEANO. El fútbol a sol y sombra.

${ }^{22}$ FATHEUER. Brasilien vom Fußball aus denken, p. 42. "Quando o jovem profissional em publicidade, Washington Olivetto, fica sabendo do que está acontecendo no Corinthians, ele inventa in nome Democracia Corinthiana, um branding perfeito. Também o slogan 'Vencer campeonatos é o menor detalhe', atribuído a Sócrates, até hoje funciona como síntese genial do espírito da época." Cf. também o capítulo "Socratic dialogue" em BELLOS, Futebol, p. 359-373.
} 
No final dos anos 70, os discursos da identidade do Brasil se fragmentam e multiplicam, conforme a realidade de um país altamente heterogêneo. ${ }^{23}$ As copas do mundo "acompanham" esta heterogeneidade discursiva numa interação mais indireta, refratada e complexa.

Assim, as copas de 1982, 1986, 1990 vivenciam uma seleção de jogo e estética extraordinários, mas que é eliminada com derrotas trágicas. Olhando para trás e numa perspectiva bem pessoal, é nesses anos que a torcida brasileira conquista para sempre o coração do público internacional, pela sua paixão e pelo sofrimento sincero à vista do mundo inteiro. A isso se junta a visão de um país sofrendo sob a ditadura, depois lutando pela democracia e então sofrendo de crises econômicas profundas. Nessa época, o futebol parece incorporar muito da força libertadora do jogo e se livrar das projeções identitárias nacionais ou nacionalizantes. A seleção "mágica” de 1982, eliminada pela Itália, nos faz lembrar o momento utópico do futebol-arte, a sua melancolia, perdida nas décadas posteriores: “Die 'Tragödie von Sarrià' [...] hatte grundlegende Auswirkungen auf die weitere Entwicklung des brasilianischen Spielstils. Überall wurde öffentlich diskutiert, ob man angesichts der Niederlage weiterhin Fußball als Kunst spielen könne”. ${ }^{24}$

\section{FUTEBOL DE RESULTADOS (1994-2014)}

É mesmo interessante observar como se inicia uma mudança fundamental com os anos 90. O Brasil é marcado pelo advento do neoliberalismo, pelo processo de impeachment contra o Presidente Collor, por vários escândalos de corrupção massiva e pelo plano Real. Em suma, é um Brasil confuso que, com um futebol "pouco brasileiro", ganha finalmente a quarta copa em 1994 nos pênaltis:

\footnotetext{
${ }^{23}$ Cf. COSTA. A trajetória da queda, p. 161.

${ }^{24}$ CURI. Brasilien, p. 63. "A 'tragédia de Sarrià' [...] teve efeitos fundamentais para a evolução do jogo no Brasil. Por todas as partes se discutia se, depois dessa derrota, seria possível continuar jogando o futebol como uma arte".
} 
Im Juli, während in den USA und in den Fernsehern die WM lief, verkündete Fernando Henrique Cardoso den Plano Real, die neue an den Dollar gekoppelte Währung. [...] Sowohl für Cardoso als auch für Parreira bedeutete Modernität keine magische Formel, beide setzten nicht auf einen brasilianischen Sonderweg. ${ }^{25}$

Esse novo "realismo" sofre uma ruptura quatro anos depois, quando o Brasil não se conforma com a derrota na final de Paris em 1998. Uma derrota que evidencia de forma até então inusitada o entrelaçamento do futebol com o comércio e com o simbolismo nacional, o papel duvidoso do novo patrocinador da seleção, Nike, na escalação de Ronaldo para a final vira até objeto de uma CPI. 0 país em vias de consolidação se espelha num futebol "realista" e tão pouco brasileiro, ao mesmo tempo as CPIs do futebol fazem parte de uma recaída na crise irracional e nos escândalos dos anos anteriores:

The disappointment with the results of the 1998 finals ended up triggering a politicised flood of explanations as a consequence of a collective football history which had slowly formed in Brazilian thought. National identity through football had already been consolidated, and was no longer at stake. [...] The 1998 defeat, the loss at the Olympic Games shortly thereafter. and accusations that the coach had profited from the participation of certain players in the team, led to two investigating committees in the National Congress - one concerned with the CBF-Nike contract and the other with alleged illegal contracts among the administrators of Brazilian football. ${ }^{26}$

Ao mesmo tempo, em 1998 a seleção brasileira é a pioneira na aplicação da nova lógica mercantilista do futebol nacional, transformando a camisa verdeamarela em marca de valor extraordinário. ${ }^{27}$ Essa lógica mercantilista e de uma comercialização total, é objeto de numerosos estudos e de reflexões preocupadas com o futuro do futebol brasileiro na sua dimensão cultural e importância simbólica. ${ }^{28} 0$ "jogo bonito" vira marca dos patrocinadores e deixa de dominar os campos. Essa evolução corresponde à transformação da função simbólica do

${ }^{25}$ ZEYRINGER. Fußball, p. 240. "Em julho, enquanto nos EUA e na televisão passava a Copa do Mundo, Fernando Henrique Cardoso iniciou o Plano Real, a nova moeda ligada ao dólar. [...] Tanto para Cardoso quanto para Parreira, modernidade não era uma fórmula mágica, ambos renunciavam a uma via brasileira".

${ }^{26}$ LEITE LOPES. Transformations in National Identity through Football in Brazil, p. 85-86. Cf. BELLOS. We lost because we didn't win, p. 317-357.

${ }_{27}$ ZEYRINGER. Fußball, p. 405ss.

28 ROCCO JR. Brasil 1 × 7 Alemanha, p. 170-171. Também EICHLER. 7-1 - Das Jahrhunderspiel, reflexiona sobre essa época como a origem da crise atual do futebol brasileiro. 
futebol, que já não une uma nação unificada em diversos planos pela força política. O futebol vira uma das máscaras que projetam uma unidade superficial e com caráter de evento. Esta mudança marca o futebol mundial na década seguinte, que vivencia um pentacampeonato em 2002, que é mais evento do que esporte, e que não consegue esconder a profunda e estrutural crise esportiva que vai surgindo no futebol brasileiro.

No contexto nacional, o futebol já não possui alta qualidade, as exportações de jogadores cada vez mais jovens impedem a evolução dos times e dos campeonatos, os craques brasileiros globais quase não têm mais ligação substancial com o país. Assim, as copas de 2006 e 2010 são no máximo medíocres, com a torcida decepcionada e - junto com ou instigada pela mídia - sempre à procura de um culpado, de um bode expiatório. É uma evolução estranha e complexa, que culmina de forma ainda mais complicada na copa de 2014, evento quando os sonhos da nação desenvolvida e modernizada se chocaram com os protestos sociais e anticorrupção; quando a dramaturgia da "Copa das Copas" se desfaz na repetição - ou até intensificação - do trauma de 1950, evidenciando ainda mais nitidamente a crise política, social e institucional do país e também a crise profunda do futebol brasileiro como um todo.

\footnotetext{
Brasilien verfolgte mit seiner WM-Bewerbung ebenfalls die Zielsetzung, das Land wirtschaftlich $\mathrm{zu}$ positionieren und international den Eindruck einer aufstrebenden Wirtschaftsmacht, einer „emerging power“, zu untermauern [...]. Wechselnde Regierungen hatten nach der Demokratisierungswelle der 1990er Jahre verstärkt auf wirtschaftliche Modernisierung gesetzt. Der WM-Zuschlag reihte sich damit im öffentlichen Bewusstsein des Landes ein in eine Riege von wirtschaftlichen Erfolgen, so etwa gesteigerte Staatseinnahmen durch Ölvorkommen vor der Küste, milliardenschwere Börsengänge, ein wachsendes Bruttoinlandsprodukt, aber auch eine Verbesserung der sozialen Lage und eine Reduzierung der Arbeitslosenquote. ${ }^{29}$
}

\footnotetext{
${ }^{29}$ MITTAG; EBBINGHAUS. Juntos num só ritmo, p. 142. "Com a candidatura para sediar a copa, o Brasil também perseguia o objetivo de posicionar o país em termos econômicos e de consolidar internacionalmente a imagem de um 'poder econômico emergente' [...]. Os diferentes governos nos anos 1990, depois da volta à democracia, apostaram fortemente na modernização econômica. Na consciência coletiva nacional, sediar a copa de futebol se inseria numa série de sucessos econômicos, como o aumento dos ingressos públicos com os jazimentos de petróleo no litoral, entradas na bolsa com valores de bilhões de Reais, o crescimento do Produto Interno Bruto, mas também a melhora da situação social e a redução da taxa de desemprego."
} 


\section{CONSIDERAÇõES FINAIS}

As reformas realizadas nos estádios já existentes e a concepção dos novos estádios construídos para a copa de 2014 evidenciam que o megaevento providenciou uma ocasião para avançar com mudanças muito mais profundas no sistema futebolístico brasileiro. Desde então, o público no estádio está minguando, as imagens de "clássicos" brasileiros com tribunas (semi)-desertas deprime, torcedores de muitos anos se queixam dos preços elevados. Em combinação com o medo das classes média e alta que preferem cada vez mais não assistir aos jogos nos estádios, o futebol brasileiro está tomando um rumo bem particular de virtualização através da televisão paga. ${ }^{30}$

Também não há mudança na política esportiva e educativa dos clubes. 0 problema da exportação em massas de jogadores jovens como forma de investimento de alto risco, num circuito global envolvendo clubes, técnicos e agentes, continua crescendo e o nível técnico dos "grandes" clubes brasileiros continua diminuindo. ${ }^{31}$ Esse é o outro extremo da polaridade dentro da qual surgem fenômenos extraordinários como Neymar Jr., até princípios de 2018, o jogador mais caro da história.

Os protestos que acompanhavam a Copa das Confederações em 2013 evidenciaram a dinâmica política entre o jogo e seus diferentes atores. Visto desde fora, os protestos não apontavam em uma direção determinada, mas para o público internacional ficou visível que no Brasil virtualmente tudo passa pelo futebol e pode ser articulado através dele:

Gehen alle auf die Straße, weil ein allgemeiner Unmut sie erfasst hat, dann spiegelt sich das eben auch in der Vielfältigkeit der Ansichten, politischen Positionierungen und Forderungen wider. Dennoch sind sich die meisten Beobachter_innen weitgehend einig, dass die Proteste sich gegen die chronischen Defizite bei den öffentlichen Gütern - Bildung, Gesundheit,

\footnotetext{
${ }^{30}$ Conferir, por exemplo, os números preocupantes no portal GE para os campeonatos brasileiros em 2017: https://bit.ly/1FPfdG1.

${ }^{31} \mathrm{Um}$ fenômeno que vem marcando a história recente do futebol brasileiro, como se pode verificar em RIAL. Rodar; JÖNSSON Die Spielerfabrik.
} 
Transport - gerichtet haben, angesichts milliardenschwerer Ausgaben des Staates für andere Belange (WM, Olympia, prestigeträchtige Großprojekte etc.). ${ }^{32}$

Ficou visível que os problemas estruturais históricos continuam sem resolver, em paralelo aos dilemas de todas as reformas empreendidas pelos governos de Fernando Henrique Cardoso, Lula e Dilma Rousseff. A corrupção e principalmente a exclusão social até hoje são os problemas-chave e que não experimentaram mudança significativa. ${ }^{33}$ Ambas ficaram à plena vista do mundo inteiro em torno da Copa de 2014, e a seleção brasileira sucumbiu a essa pressão gigantesca e/ou simplesmente não tinha a qualidade necessária para se impor, pagando pelos pecados estruturais do futebol nacional, já evidentes nas atuações de 2006 e 2010. Em um primeiro levantamento depois da copa de 2014, Flávio de Campos afirma: "A principal característica da Copa de 2014, que marcou definitivamente a história do futebol, foi a intensa politização. Futebol e política entraram em campo com uma disposição tática nunca vista". ${ }^{44}$ E também explica:

\begin{abstract}
Em Brasília, na cerimônia de abertura, a presidenta Dilma foi vaiada, no lado de dentro do Estádio Mané Garrincha, por uma maioria de integrantes das classes médias confortavelmente instalada nas cadeiras coloridas da arena esportiva. Do lado de fora, a presidenta foi vaiada por representantes de movimentos populares, que, paradoxalmente, denunciavam também o processo de elitização e de exclusão dos setores subalternos dos espaços destinados à assistência das práticas esportivas. ${ }^{35}$
\end{abstract}

O governo acreditando poder controlar e aproveitar a copa e a seleção, o público criticando e questionando a copa, mas apoiando a seleção freneticamente até o triste fim... Essas observações fazem perguntar: Quem cantava o hino brasileiro? E para qual Brasil nos jogos da seleção? A própria seleção tentando se solidarizar com os protestos e a torcida, mas sem poder contribuir com bom

\footnotetext{
${ }^{32}$ RUSSAU. Die Juni-Proteste, p. 153. "Se todos saem para as ruas porque uma revolta geral os motiva, isso também se reflete na variedade das perspectivas, das posições e reivindicações políticas. Porém, a maioria dos observadores concorda em que os protestos se dirigiam contra os déficits permanentes nos bens públicos - educação, saúde, transporte público -, frente aos gastos gigantescos do Estado para outros projetos (copa do mundo, jogos olímpicos, projetos de grande porte e prestígio etc.)".

${ }^{33}$ BOECKLE. Soziale Ungleichheit, p. 437.

${ }^{34}$ CAMPOS. A copa de política em um país do futebol, p. 37.

${ }^{35}$ CAMPOS. A copa de política em um país do futebol, p. 32.
} 
futebol... Tudo isso mostra a nova dimensão fragmentada e complexa midiática e discursiva em torno do futebol.

Quem se mostrou atrasada foi a FIFA insistindo na natureza "apolítica" do futebol, exigindo que o governo brasileiro desse fim às manifestações e protestos no âmbito da Copa. Porém, essa posição está ela mesma no centro de um conflito essencialmente político em torno ao "jogo" ludopédico. Mirco Drewes, de maneira muito pregnante, desmonta essa posição "oficial" e mostra o seu equívoco frente à realidade sociocultural do futebol, particularmente no Brasil, onde a oposição entre futebol e política - defendida pelo então presidente da FIFA Joseph Blatter não corresponderia à realidade nacional:

Der Fußball in Brasilien war stets ein Politikum. [...] Diesem Wesen des Spiels, seiner Doppelrolle als Substrat der Wirklichkeit und virtuelles gesellschaftliches Labor, verdankt sich die Vorreiterrolle des Fußballs bei der Überwindung der Rassendiskriminierung, auch seine Rolle als systemstabilisierendes Opium fürs Volk, sowie seine starke Rolle bei der Demokratisierung des Landes. [...] Der Brasilianer liebstes Spiel hat seine Bedeutung für die Selbstfindung des Landes nicht verloren, im Gegenteil. Der Fußball scheint seinen Beitrag zur Ausbildung einer kritischen Zivilgesellschaft auch heuer zu leisten. ${ }^{36}$

Isso ficou visível depois da eliminação do Brasil, caso para o qual tantos "entendidos" internacionais tinham anunciado o início de violentos protestos políticos, mas que acabou relevando a uma torcida sensata e refletida. Também não houve derrota de Dilma Rousseff nas eleições por causa da copa "perdida", e o subsequente processo do impeachment mostrou a profundidade da crise política do país, já muito além do futebol. Desde então a identidade do futebol e a identidade do Brasil estão mais uma vez em jogo, sendo renegociadas e disputadas em sua ampla dimensão política.

\footnotetext{
${ }^{36}$ DREWES. Samba tanzt der Fußballgott, p. 306. "O futebol no Brasil sempre foi uma questão política. [...] A essa natureza do jogo, ao seu papel duplo como substrato da realidade e laboratório social virtual, se deve o pioneirismo do futebol na superação da discriminação racial, também o seu papel como 'ópio para o povo' estabilizador do sistema, assim como o seu forte papel na democratização do país. [...] O jogo predileto dos brasileiros não perdeu a sua importância na autodefinição da nação, ao contrário. O futebol parece continuar contribuindo, ainda hoje, a sua parte à formação de uma sociedade civil crítica". Também cf. ZIMMER, Lieber Brot als Spiele.
} 
Die Proteste vom Juni 2013 haben die Geschichte von Brasilien als »Siegerland« (Präsidentin Dilma Rousseff) gründlich verdorben. In der säkularen Debatte zwischen dem futebol de resultados und dem futebol-arte haben natürlich nach 2010 die Vertreter_innen des Letzteren wieder Auftrieb bekommen. Das Insistieren auf dem Fußball der Mehr-Lust wird somit zu einer Gegenerzählung gegen ein Brasilien, das seine Identität im wirtschaftlichen Erfolg, in der Einordnung in den Weltmarkt sucht. ${ }^{37}$

Essa lógica mercantilista e de uma comercialização total, é objeto de numerosos estudos e de reflexões preocupadas com o futuro do futebol brasileiro na sua dimensão cultural e importância simbólica:

Sem estratégia clara e com ações de comunicação confusas e desconexas, sempre privilegiando as relações comerciais e de patrocínio, a comunicação da CBF na Copa do Mundo mostrou pouca objetividade e ausência completa de coerência, evidenciada pelas ações dispersas dos atletas nas redes sociais. As necessidades esportivas da seleção brasileira, e seu foco e concentração na competição, foram desprezados e deixados de lado por uma estratégia fraca e sem integração entre os diversos campos e ferramentas da comunicação. A CBF conseguiu, assim, colocar o esporte como refém da comunicação e do mercado. $^{38}$

O interessante, no caso brasileiro, é agora a volta do ideal do futebol-arte que, com seu desprezo pela mera orientação pelos resultados, corresponderia com os sonhos de uma recuperação da inocência ou autenticidade do futebol no contexto sociocultural.

Die Idee des futebol-arte passt in eine Zeit, in der sich die großen Erzählungen der Nation, des Vaterlandes und der Identität auflösen. Aus den imaginierten Gemeinschaften der Nation drohen - so der argentinisch-mexikanische Kulturwissenschaftler Néstor García Canclini - Interpretationsgemeinschaften von Konsument_innen zu werden. Identitäten werden immer mehr durch den Konsum bestimmt und »sind davon abhängig, was man besitzt «. ${ }^{39}$

\footnotetext{
${ }^{37}$ FATHEUER. Brasilien vom Fußball aus denken, p. 88. "Os protestos de junho de 2013 desacreditaram profundamente a narrativa do Brasil enquanto 'país vencedor' (Presidenta Dilma Rousseff). Na discussão secular entre o 'futebol de resultados' e o 'futebol-arte', evidentemente, depois de 2010 os adeptos do último voltaram a voar alto. Insistir no futebol com prazer adicional, assim se torna contra-narrativa contra um Brasil que procura a sua identidade no sucesso econômico, na integração no mercado mundial".

${ }^{38}$ ROCCO Jr. Brasil 1 x 7 Alemanha, p. 170-171.

${ }^{39}$ FATHEUER. Brasilien vom Fußball aus denken, p. 89; "A ideia do futebol-arte combina com um tempo em que as grandes narrativas da Nação, da Pátria e da Identidade estão se dissolvendo. Segundo o estudioso da cultura Néstor García Canclini, as comunidades imaginadas da Nação estão em perigo de se transformar em comunidades de interpretação compostas por consumidores. Identidades são determinadas cada vez mais pelo consumo, e „dependem daquilo que se possui«".
} 
O Brasil político e econômico está em ruínas, pelo menos quando se aplica padrões tradicionais de democracia e bem-estar, o futebol nacional - os clubes e os campeonatos brasileiros - continuam em crise. Porém, a seleção do técnico Tite parece mesmo ter-se reencontrado enquanto time e símbolo do Brasil, tendo garantido de forma impressionante a sua vaga na copa de 2018 e voltando a jogar um futebol para além dos meros resultados. ${ }^{40}$

\section{REFERÊNCIAS}

BELLOS, Alex. The fateful final; We lost because we didn't win". In:

Futebol: the Brazilian way of life. London: Bloomsbury, 2002, p. 43-76; 317-357.

BERNECKER, Walther L.; PIETSCHMANN, Horst; ZOLLER, Rüdiger. Eine kleine Geschichte Brasiliens. Frankfurt am Main: Suhrkamp, 2000.

BOECKLE, Bettina. Soziale Ungleichheit und Brasiliens Politikantwort in den neunziger Jahren. Ein Rückblick. In: COSTA, Sérgio; KOHLHEPP, Gerd; NITSCHACK, Horst; SANGMEISTER, Hartmut (orgs.). Brasilien heute. Geographischer Raum, Politik, Wirtschaft, Kultur. Frankfurt am Main: Vervuert, 2010, p. 429-439.

CALDAS, Waldemyr. Brasilien. In: EISENBERG, Christiane (org.). Fußball, soccer, calcio. Ein englischer Sport auf seinem Weg um die Welt. München: Deutscher Taschenbuch Verlag, 1997, p. 171-184.

CAMPOS, Flávio de. A copa de política em um país do futebol. In: MARQUES, José Carlos (org.). A copa das copas? Reflexões sobre o Mundial de Futebol de 2014 no Brasil. São Paulo: Edições Ludens, 2015, p. 31-38.

CORNELSEN, Elcio. A memória do trauma de 1950 no testemunho do goleiro Barbosa. Esporte e Sociedade, v. 8, n. 21, 2013.

COSTA, Leda Maria da. A trajetória da queda. As narrativas da derrota e os principais vilões da seleção brasileira em Copas do Mundo. Tese de Doutoramento. Instituto de Letras da UERJ, Rio de Janeiro, 2008.

CURI, Martin. Brasilien. Land des Fußballs. Göttingen: Die Werkstatt, 2013.

CURI, Martin. Friedenreich. Das vergessene Fußballgenie. Göttingen: Die Werkstatt, 2009.

DAMATTA, Roberto. Antropologia do óbvio: notas em torno do significado social do futebol brasileiro. Revista USP, n.22, p. 10-17, 1994.

\footnotetext{
${ }^{40}$ WIECHMANN. Schlechte neue Welt, p. 149-154, resume para o público alemão o simbolismo do Maracanã enquanto templo democrático do futebol brasileiro, destruído - "desalmado" (nas palavras de Juca Kfouri) - pela reforma para 2014, e desde então sempre vazio, até nos clássicos, ou completamente abandonado pelos clubes cariocas.
} 
DREWES, Mirco. Samba tanzt der Fußballgott. Brasiliens Fußball zwischen Genie und Wahnsinn. Berlin: Vergangenheits-Verlag, 2013.

DUNKHORST, Jan. Linker Fußball? Rechter Fußball? César Luis Menotti als Utopist des Wahren, Guten und Schönen im Fußball. In: AZZELLINI, Dario; THIMMEL, Stefan (orgs.). Futbolistas. Fussball und Lateinamerika: Hoffnungen, Helden, Politik und Kommerz. Berlin: Assoziation A, 2006, p. 86-94.

EICHLER, Christian. 7:1 - Das Jahrhundertspiel. Als der brasilianische Mythos zerbrach und Deutschlands vierter Stern aufging. München: Droemer, 2015.

FATHEUER, Thomas. Brasilien vom Fußball aus denken. In: DILGER, Gerhard; FATHEUER, Thomas; RUSSAU, Christian; THIMMEL, Stefan (orgs.). Fußball in Brasilien. Widerstand und Utopie. Von Mythen und Helden, von Massenkultur und Protest. Hamburg: VSA, 2014, p. 48-89.

FATHEUER, Thomas. Fragmente einer Theorie des brasilianischen Fußballs. In: AZZELLINI, Dario; THIMMEL, Stefan (orgs.). Futbolistas. Fussball und Lateinamerika: Hoffnungen, Helden, Politik und Kommerz. Berlin: Assoziation A, 2006, p. 112-119.

FILHO, Mário. O negro no futebol brasileiro. Segunda edição, ampliada em forma definitiva. Rio de Janeiro: Civilização Brasileira, 1964.

FREYRE, Gilberto. Prefácio. In: FILHO, Mário. O negro no futebol brasileiro. Segunda edição, ampliada em forma definitiva. Rio de Janeiro: Civilização Brasileira, 1964, p. IX-XII.

GALEANO, Eduardo $H$. El fútbol a sol y sombra. México, D. F.: Siglo Veintiuno Editores, 2010.

GUEDES, Simoni Lahud. El Brasil reinventado: notas sobre las manifestaciones durante la Copa de las Confederaciones. Nueva Sociedad, n. 248, p. 89-100, 2013.

HENRIQUES, Claudio Cezar; ARAUJO, Lúcia Deborah. À sombra das crônicas imortais. Humanidades, v. 29, n. 1, p. 11-21, 2014.

HENRIQUES, Claudio Cezar. Estilística e futebol: um estudo das crônicas ludopédicas de Nélson Rodrigues. In: DE ROSA, Gian Luigi; CHULATA, Katia de Abreu; DEGLI ATTI, Francesca; MORLEO, Francesco (orgs.). De volta ao futuro da língua portuguesa. Atas do V SIMELP. Simpósio Mundial de Estudos de Língua Portuguesa 2017. Salento: ESE - Salento University Publishing, 2017, p. 1853-1867.

IHLE, Holger. Die Fußball-WM 2014 in Brasilien als Sportgroßveranstaltung kommunikations - und politikwissenschaftliche Zugänge. In: IHLE, Holger; MEYEN, Michael; MITTAG, Jürgen; NIELAND, Jörg-Uwe (orgs.). Globales Mega-Event und nationaler Konfliktherd. Die Fussball-WM 2014 in Medien und Politik. Wiesbaden: Springer VS, 2017, p. 3-27.

JÖNSSON, Henrik. Die Spielerfabrik. Wie Brasilien die Welt mit Fußballern versorgt. 11 Freunde, n. 53, 2006, p. 30-46.

KAZ, Leonel; COSTA E SILVA, Paulo. Dando tratos à bola: futebol e Brasil. Revista USP, n. 99, p. 67-78, 2013. 
LEITE LOPES, J. Sérgio. Transformations in National Identity through Football in Brazil: Lessons from Two Historical Defeats. In: MILLER, Rory; CROLLEY, Liz (orgs.). Football in the Americas: fútbol, futebol, soccer. London: Institute for the Study of the Americas, 2007, p. 75-93.

MIRANDA PEREIRA, Leonardo Affonso de. Footballmania. Uma história social do futebol no Rio de Janeiro, 1902-1938. Rio de Janeiro: Nova Fronteira, 2000.

MITTAG, Jürgen; EBBINGHAUS, Judith. Juntos num só ritmo? Brasilien und FIFA im Spannungsfeld der Interessen um die Vergabe und Vorbereitung der Weltmeisterschaft 2014. In: IHLE, Holger; MEYEN, Michael; MITTAG, Jürgen; NIELAND, Jörg-Uwe (orgs.). Globales Mega-Event und nationaler Konfliktherd. Die Fußball-WM 2014 in Medien und Politik. Wiesbaden: Springer VS, 2017, p. 135-154.

MUNO, Wolfgang. Fußball und Politik in Lateinamerika. In: MUNO, Wolfgang, SPILLER, Roland (orgs.). “Gracias, Dios, por el fútbol”. Diskurse rund um den Fußball in Lateinamerika. Mainz: Veröffentlichungen des Interdisziplinären Arbeitskreises Lateinamerika, 2006, p. 6-25.

PERDIGÃO, Paulo. Anatomia de uma derrota. Edição revisada e ampliada. Porto Alegre: L\&PM, 2000.

RIAL, Carmen. Rodar: a circulação dos jogadores de futebol brasileiros no exterior. Horizontes Antropológicos v. 14, n. 30, 2008, p. 21-65.

ROCCO JR., Ary José. Brasil 1 × 7 Alemanha: $O$ dia em que a comunicação a favor do esporte goleou o esporte a favor da comunicação. In: MARQUES, José Carlos (org.). A copa das copas? Reflexões sobre o Mundial de Futebol de 2014 no Brasil. São Paulo: Edições Ludens, 2015, p. 149-174.

RUSSAU, Christian. Die Juni-Proteste. In: DILGER, Gerhard; FATHEUER, Thomas; RUSSAU, Christian; THIMMEL, Stefan (orgs.). Fußball in Brasilien. Widerstand und Utopie. Von Mythen und Helden, von Massenkultur und Protest. Hamburg: VSA, 2014, p. 146-158.

VEJMELKA, Marcel. O futebol como palco em Nelson Rodrigues. Revista da Academia Brasileira de Filologia, Nova Fase, n. XIV, p. 138-162, 2014.

WIECHMANN, Jan-Christoph. Schlechte neue Welt. 11 Freunde, n. 151, p. 149-154, 2014.

ZANIN, Luiz. Nelson Rodrigues e o mito do futebol. Revista USP, n. 96, p. 136144, 2012-13.

ZEYRINGER, Klaus. Fußball. Eine Kulturgeschichte. Aktualisiert und erweitert. Frankfurt am Main: Fischer, 2014.

ZIMMER, Dominik. Lieber Brot als Spiele. Lateinamerika-Nachrichten, LNDossier 10, p. 8-12, 2014.

Recebido para publicação em: 15 dez. 2017. Aprovado em: 22 jan. 2018. 